\title{
Mitigation of GHG Emission by Replacing Diesel Buses with Electric Buses in Kathmandu Valley "A Case Study of Sajha Yatayat"
}

\author{
Anil Nepal ${ }^{*}, 1$ \\ ${ }^{1}$ Department of Applied Science and Chemical Engineering, Pulchowk Campus, Institute of Engineering, \\ Tribhuvan University, Kathmandu, Nepal \\ *Corresponding Email: anil.nepa1602@gmail.com
}

\begin{abstract}
The net benefit of replacing diesel bus by electric bus in Kathmandu Valley is found positive. The net benefits of replacing diesel bus by electric bus is found to be NRs 8,31,776.So, per bus per year in the context of Sajha yatayat, the government should encourage the introduction of electric bus inside Kathmandu Valley. The four types of scenarios including one Business as usual scenario and other three different replacement scenarios, namely, ESB25, ESB50 and ESB100 for the period 2019-2035 are analyzed in this study. The 15.5, 31.2 and 62.4 Million Mega joule of energy can be saved in ESB25, ESB50 and ESB100 scenarios respectively in comparison to BAU scenario. The cumulative cost saved from avoided energy is $0.12,0.25$ and 0.5 million US dollars at constant price of 2019 under ESB25, ESB50 and ESB100 scenarios respectively in comparison to BAU scenario. The total GHG emissions avoided is 15.6, 31.2 and 62.41 thousand tons under ESB25, ESB50 and ESB100 scenarios respectively in comparison to BAU scenario. The cumulative revenue generated is $0.15,0.31$ and 0.62 million US dollars at constant price of 2019 under ESB25, ESB50 and ESB100 scenarios respectively in comparison to BAU scenario. Since net benefit of replacing both old and new diesel bus is positive, ESB100 scenario is the best option to replace diesel buses by electric uses.
\end{abstract}

Keywords: Electric Buses, Energy Consumption, GHG Emissions

\section{INTRODUCTION}

In recent years, scholars, policy-makers, and the general public in many parts of the world have become increasingly concerned over health and environmental damages associated with air pollution. As urban transport is among the most important contributors to urban air pollution, this concern has led to a heightened interest in Electric Vehicles (EVs) as well as other environmentally friendly alternative forms of transport. Consequently, many industrialized countries have revised the policies to encourage the use of alternative-fuel vehicles. In the United States, for example, California, New York and a few other states had mandates that required $10 \%$ of all motor vehicles sold after 2003 to be zero-emissions 
vehicles or, in other words, EVs. California, in particular, provides certain sales credit to encourage the purchase of EVs (Bhatta \& Joshi 2004). Decreasing air quality and rapidly increasing fuel price with frequent fuel strikes has increased the interest of people of Kathmandu valley towards electrical vehicle. Public awareness about benefits of reducing air pollution level by replacing ICEVs by EVs is in increasing rate. Many researchers, advocates and environmentalists are encouraging government to make favorable policies to expand electrical vehicle system in Kathmandu.

\section{PROBLEM STATEMENT}

Nepal imports $100 \%$ of fossil fuel it needs, since there are not any natural fossil fuel reserves found yet in Nepal. Nepal is expending huge portion of its budget to buy fossil fuel mainly from India. The demand of petroleum products is about 1.8 million tons per annum with annual increase by $20 \%$ whereas petroleum products constitute about $11 \%$ of total energy consumed in Nepal (MOF, 2019). In 2012, the valley consumed $46 \%$ of the total petrol and $16 \%$ of the total diesel sales in Nepal (NRB,2012). The price of fossil fuel is increasing very rapidly in recent years. In 2002/11/23, the price of diesel was 26.50 NRs/L, whereas 17 years later in 2019/12/21, the price of diesel increased to 97.5 NRs/L (NOC, 2019). In other words, the price of diesel has been increased by $270 \%$ in the period of 17 years (NOC, 2019). But in same duration, price of electricity increased by only $20 \%$ maximum (NEA, 2019).The above difference in increment of price of diesel and electricity favors strongly to replace diesel fueled vehicles by electrical vehicles.

\section{LITERATURE REVIEW}

\subsection{ENERGY CONSUMPTION IN NEPAL}

Total energy consumption in Nepal in year 2008/09 was 401 million GJ. The same in year 2000/01 was 335 million GJ. Total energy consumption in the country in this period is increased by about $2.4 \%$ annually which is about in line with the present growth of GDP to some extent. The residential sector ac-counts for the major share of energy consumption (89.1\%), followed by transport (5.2\%), industry $(3.3 \%)$, commercial $(1.3 \%)$ and then the agricultural and others. Transport sector consumed 14 million GJ of energy in year 2000/01 which was increased to 21 million GJ in year 2008/09. Total petroleum consumption in year 2008/09 was 33 million GJ.

\subsection{AIR POLLUTION STATUS OF KATHMANDU VALLEY}

The ambient air quality of Kathmandu valley is very poor, comparable to some of the most polluted cities in the world. In terms of PM10 pollution, for example, it outranks cities like Kolkata, Mumbai and Mexico City. Kathmandu average annual PM10 concentration of 198 in 2003 is well above the National guideline of (CEN, 2003).

\subsection{SAJHA YATAYAT}

Sajha Yatayat is a cooperative public transportation organization which was established n 1961/1962 to provide efficient and affordable public transportation to commuters in Kathmandu Valley, as well to inter-district travelers. In the last decade, the organization suffered some institutional turbulence, but now it has been revived, with the participation of the Government of Nepal, as a cooperative 
organization. Its goal is to provide public transportation that is efficient, transparent and professional in terms of service delivery.

\subsection{COST-BENEFIT ANALYSIS IN PUBLIC TRANSPORT ELECTRIFICATION}

Cost-Benefit analysis is a decision-making tool that is used to systematically develop useful information about desirable and undesirable effects of public projects. In a sense, we may view benefit-cost analysis in the public sector as profitability analysis in the private sector. In other words, benefit-cost analysis attempts to determine whether the benefits of a proposed public activity outweigh the costs (Park, 2011).

\section{METHODOLOGICAL FRAMEWORK}

\subsection{FIELD SURVEY}

- Data Collection from Sajha Yatayat

- Calculation of Maintenance cost and Fuel Consumption

- Estimation of Passenger-km

\subsection{DATA ANALYSIS}

- Travel Demand Estimation

- Vehicle kilometers

- Data flow in LEAP model

- Scenario description and relevancy

\section{BENEFIT- COST ANALYSIS}

\subsection{ESTIMATION OF COST}

Since diesel and electric buses are not manufactured in Nepal, the production cost of vehicle is the purchasing cost of vehicle before addition of any type of tax. In other words, production cost is the total cash outflow from nation. The production cost of diesel bus is taken as the reference of Ashok Leyland 54 Seater Passenger bus and that of electric bus is taken as the reference of New Bus 54 seater Chinese electric bus introduced by Sundar Yatayat Pvt. Ltd was claimed very high (NRs 1,64,00,000) but during the last visit to China while visiting the Foton Motor Group, Beijing which is the main Producer of Electric Vehicles operating in Beijing and the quotation of the different model of the Buses and for the 54 Seater i.e. $12 \mathrm{~m}$ long bus the was gotten with quoted price of 80000 USD. The current market price of Ashok Leyland bus is NRs. 55,00,000(From Official Dealer) and that of electric bus described above is NRs 1,150,000 in Nepal. The government charges $225 \%$ customs duty and $13 \%$ VAT on diesel vehicle and 10\% customs duty and 13\% VAT on electric vehicle. 
Table 1: Estimation of cost

\begin{tabular}{|l|l|l|l|l|}
\hline S.N. & Cost Item $(\mathrm{NRs} / \mathrm{Km})$ & New diesel bus & Electric bus & Electric bus-New diesel bus \\
\hline 1. & Production & 5.54 & 11.59 & 6.05 \\
\hline 2. & Battery & 0.52 & 3.36 & 3.11 \\
\hline 3. & Maintenance/Repair & 5.99 & 2.39 & 3.6 \\
\hline 4. & Fuel/Energy & 30.80 & 11.28 & 19.52 \\
\hline 5. & Total & 23.01 & 17.44 & 13.96 \\
\hline
\end{tabular}

\subsection{ESTIMATION OF BENEFITS}

The method used here to calculate net benefits is similar to Bhatta \& Joshi (2004). The emission factors for different pollutants are given in column (a) of figure 4.2a and 4.2b. The costs due to health damage from polluting gases given in column (b) for context of United States. The emission factors and un-adjusted damage cost used in table 4.2a and 4.2b are taken as used by Bhatta Joshi (2004). In order to use these damage estimates in context of Nepal, these damage estimates have been multiplied by purchasing power parity(GDP) adjusted per capita income (PPP-adjusted PCP) ratio between US and Nepal, and given in Table 4.2a and 4.2b as adjusted damage in column(c). The GDP adjusted per capita income of United States and Nepal are \$59,532 and \$2,682 in 2017 (World Bank, 2017).

\begin{tabular}{|lllllll|}
\hline S.N & Pollutants & $\begin{array}{l}\text { Emission } \\
(\mathrm{g} / \mathrm{km})\end{array}$ & $\begin{array}{l}\text { Unadjusted } \\
\text { damage } \\
(\text { Cents/gm }) \\
(\mathrm{b})\end{array}$ & $\begin{array}{l}\text { Adjusted } \\
\text { damage } \\
(\mathrm{Cents} / \mathrm{gm}) \\
(\mathrm{c})\end{array}$ & $\begin{array}{l}\text { Adjusted } \\
\text { damage } \\
(\mathrm{NRs} / \mathrm{g}) \\
(\mathrm{d})\end{array}$ & $\begin{array}{l}\text { Damage } \\
(\mathrm{NRs} / \mathrm{km})\end{array}$ \\
\hline 1 & $\mathrm{PM} 10$ & 1.050 & 44.648 & 2.011455 & 229.3059 & 2.407712 \\
\hline 2 & $\mathrm{NO} 2$ & 9.100 & 1.856 & 0.083615 & 9.532156 & 0.867426 \\
\hline 3 & $\mathrm{SO} 2$ & 0.273 & 3.248 & 0.146327 & 16.68127 & 0.04554 \\
\hline 4 & $\mathrm{CO}$ & 1.904 & 0.00232 & 0.000105 & 0.011915 & 0.000227 \\
\hline 5 & $\mathrm{CO} 2$ & 541.5 & 0.00336 & 0.000151 & 0.017256 & 0.093444 \\
\hline 6 & $\mathrm{NMVOC}$ & 0.675 & 0.10788 & 0.00486 & 0.554057 & 0.00374 \\
\hline Total & & & & & & 3.418088 \\
\hline
\end{tabular}

The net benefit of replacing old diesel bus with electric bus was found to be NRs 8,31,776.7/year per vehicle, i.e, society will be gaining NRs. $8,31,776.7 /$ year per vehicle if diesel bus is replaced by electric bus.

\section{TRANSPORT DEMAND AND FORECAST}

\subsection{VEHICULAR POPULATION}

The average annual growth rate has been $7.22 \%$ in the last five years for Kath-mandu Valley. At this rate the population of vehicles (except 2 wheelers) will be doubled after 10 years (DOTM 2019). Travel demand estimation 


\subsection{POPULATION AND GDP ELASTICITY}

The value of population elasticity and GDP elasticity are taken as 1.44 and 0.41 respectively as assumed by Shrestha \& Rajbhandari (2009) for road passenger transport sector of Kathmandu Valley.

\subsection{FORECAST OF FUTURE PASSENGER TRAFFIC}

As per the survey conducted under this study, the total no. of diesel bus running in Kathmandu Valley is 67 and current no. of passenger/trip of diesel bus is 95.47.The electric bus is assumed to be introduced only after 2019 onwards. As shown in Figure 1 the TOD based average electricity price is calculated as $5.8 \mathrm{NRs} / \mathrm{KWh}$.

\subsection{FUEL CONSUMPTION}

Fuel consumption in transport sector is dependent upon vehicle activity, type of vehicle, specific fuel consumption and other driving parameters like speed, vehicle ages etc. (Pradhan, 2004). While in this study, parameters like specific fuel consumption, type of vehicle and the vehicle activity are taken into account for determining the fuel consumption. The trend of fuel consumption for each vehicle type in different scenarios is determined. Specific fuel consumption for the diesel bus in year 2019 is determined from primary survey from data taken from Sajha Yatayat of diesel bus. The specific fuel consumption for diesel bus is found to be 0.322 from survey. The specific fuel consumption for electric bus is taken as $1.34 \mathrm{KWh} / \mathrm{km}$ (Foton Motor Corp). The Figure 2 shows the fuel properties for each type of fuel.

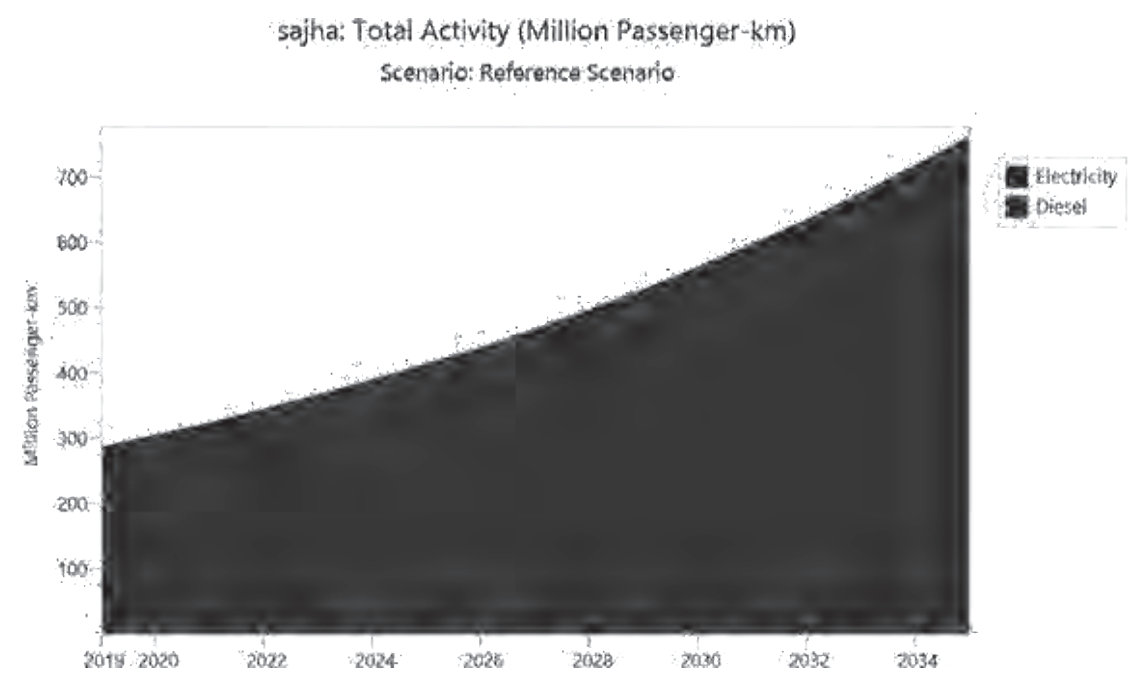

Figure 1: Forecasted passenger kilometers of existing diesel bus 


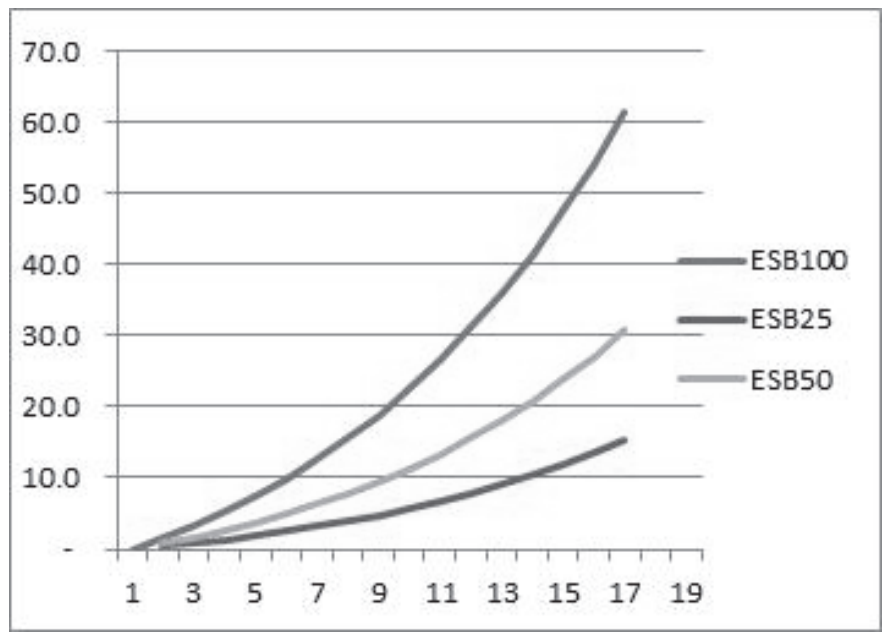

Figure 2: Fuel consumption avoided in different scenario

The fuel consumption in the alternative scenarios shows that the avoided fuel consumption in the ESB100 scenario is highest. Also total of 15.5, 31.2 and 62.1 Million Mega joule of energy can be saved in ESB25, ESB50 and ESB100 scenarios respectively in comparison to BAU scenario. The cumulative cost saved from avoided energy is 0.12 million US dollars in ESB25 scenario at con-stant price of 2019 in comparison to BAU scenario. Similarly it is 0.25 million US dollar and 0.8 million US dollar in ESB50 and ESB100 scenarios respectively.

\subsection{GHG EMISSIONS}

The air pollutants considered in this study are CO, NO2, SO2 and PM10 only. The Green houses gases taken into account in this study include CO2 and NO2 only. The one hundred year Global Warming Potential is considered in this study. The Global Warming Potentials (GWPs) of CO2 and NO2 are taken 1 and 310 t CO2 equivalent for this analysis based on LEAP-IPCC Assessment Report (1995) integrated in LEAP (2011). GWPs show their relative strength to have effect in Global Warming Potential. As shown in Figure 3, the direct GWP of NO2, for example, is defined as the cumulative direct effect on the atmosphere's energy budget resulting from one kilogram release of NO2, relative to the direct effect of a one kilogram release of $\mathrm{CO} 2$. 


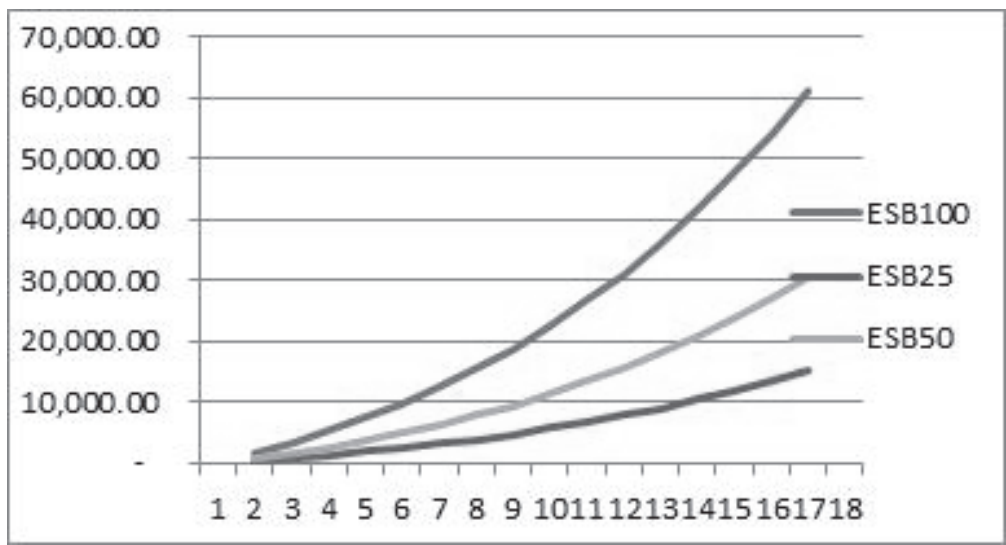

Figure 3: Cumulative revenue generated through CDM in different scenarios

\section{CONCLUSION AND RECOMMENDATIONS}

\subsection{CONCLUSION}

The net benefit of replacing diesel bus by electric bus in Kathmandu Valley is found positive. The net benefits of replacing diesel bus by electric bus are found to be NRs 8,31,776.7 So, the government should encourage the introduction of electric bus inside Kathmandu Valley. The four types of scenarios including one business as usual scenario and other three different replacement scenarios ESB25, ESB50 and ESB 100 were analyzed in the study. The total passenger service demand of bus in 2019 is 285 million passenger kilometers and this will increase to more than three folds in 2035 . The total energy consumption is increased from 39 Million Mega joule in 2019 to 101 Million Mega joule in 2035. In other units, the diesel con-sumption is increased from 975 thousand liters in 2019 to 2437 thousand liters in 2035. The 15.2, 31.1 and 62.2 Million Mega joule of energy can be avoided in ESB25, ESB50 and ESB100 scenarios respectively in com-parison to BAU scenario.

The cumulative cost saved from avoided energy is 0.12 million US dollars in EMB25 scenario at constant price of 2013 in comparison to BAU scenario. Similarly it is 0.25 and 0.5 million US dollar in EMB50 and EMB100 scenarios respectively. Relative to BAU scenario, there will be 25\%, 50\% and $100 \%$ total Emis-sions reduction in end year 2035 in EMB25, EMB50 and EMB100 scenarios respectively. The total GHG emission in 2019 is 3.6 thousand tons. In 2035, it is in-creased to 9.7 thousand tons, which is more than 3 times that of 2019. The cumulative GHG emission from 2019 to 2035 is 105.4 thousand tons. The cumulative GHG emission from 2019 to 2035 is 6,928 tons in BAU scenario. The total GHG emissions avoided is 15.6, 31.2 and 62.41 thousand tons under ESB25, ESB50 and ESB100 scenarios respectively in comparison to BAU scenario

The cumulative revenue generated from year 2019 to 2035 is $\$ 150000, \$ 310000$ and $\$ 615000$ in ESB25, ESB50 and ESB100 scenarios respec-tively at constant price of 2019. The cumulative revenue generated will be $\$ 150000, \$ 310000$ and $\$ 615000$ if carbon is traded at the price of $\$ 12$ or higher. 


\section{REFERENCES}

[1] Ale, B.B. \& Bade Shrestha, S.O., 2008. Introduction of hydrogen vehicle in Kathmandu Valley:

[2] A clean and sustainable way of transportation. Renewable Energy.

[3] Bajracharya, D. I., \& Bhattrai, N. (2016). Road Transportation Energy Demand and Environmental Emission, A case Study of Kathmandu Valley. Hydro Nepal.

[4] Bhatta, S.D. \& Joshi, D.R., 2004. Are Electric Vehicles viable in Kathmandu Valley?A costbenefit perspective. Prepared for KEVA Secretariat under USAID/NEPAL. Kathmandu: Kathmandu Electric Vehicle Aliance.

[5] Bulk, J., 2009. A cost- and benefit analysis of combustion cars, electric cars and hydrogen cars in the Netherlands. M.Sc Thesis. Netherland: Wageningen University.

[6] Carlsson, F. \& Johansson-Stenman, O., 2010. Costs and Benefits of Electric Vehicles.

[7] Transport Economics and Policy, 37(Part 1), pp.1-28.

[8] CBS, 2012. Nepal Population and Housing Census 2011. Nepal: Central Bureau of Statistics, Government of Nepal, National Planning Commision Secretariat.

[9] CEN, 2003. Health impacts of Kathmandu's air pollution. Submitted to Kathmandu Electric Vehicle Alliance. Kathmandu.

[10] Dahal, A., Joshi, M.R. \& Basnet, S.S., 2004. Feasibility study of compressed natural gas buses in Kathmandu Valley. B.E. Thesis. Nepal: Department of Mechanical Engineering IOE. Dhakal, S., 2006. ISBN: 4-88788-028-6 Urban Transportation and the Environment in Kathmandu Valley, Nepal. Japan: Institute for Global Environment Strategies (IGES). Energy Consult, 2001. Workbook on Transport Projects: Prepared. Australia: Guidebook, International Greenhouse Partnerships Office.

[11] Funk, K. \& Rabl, A., 1999. Electric versus conventional vehicles: costs and benefits in France. Transportation Research, 4(6)(Part D), pp.397-411.

[12] GAIA, 2012. What is clean development mechanism. United States: Global alliance for inceneration alternatives.

[13] ICIMOD, 2012. LCCN 2012-323210 Rapid Urban Assesment of Air Quality for Kathmandu, Nepal. Kathmandu: International Centre for Integrated Mountain Development. Larminie, J. \& Lowry, J., 2003. Electric Vehicle Technology Explained. England.

[14] MOF, 2012. National Statistical Account. Nepal: Ministry of Finance Government of Nepal.

[15] NEA, 2012. Electricity Tarrif Rates. Nepal: Nepal Electricity Authority.

[16] Nepal, S.M., 2006. Impact of transport policies on energy use and emissions. In Preceeding of the Institution of Civil Engineers., 2006.

[17] NRB, 2012. The Share of Kathmandu Valley in the National Economy. Kathmandu: Nepal Rastra Bank.

[18] Pradhan, S., 2004. An investment option in transport sector through Clean Development Mechanism: A case study of trolley buses in Ring Road. M.Sc. Thesis. Kathmandu: Department of Mechanical Engineering IOE.

[19] Shakya, S.R. \& Shrestha, R.M., 2011. Transport sector electrification in hydropower resource rich developing country: Energy security, environmental and climate change co- benefits. Energy for Sustainable Development, 15, pp.147-59.

[20] Shrestha, R.M. \& Rajbhandari, S., 2009. Energy and Environmental Imlications of Carbon Emission Reguction Targets: Case of kathmandu Valley. Energy policy, 38, pp.4818-27. TERI, 2003. Baselines for Renewable Energy Projects under Clean Development Mechanism. Unpublished Draft Report, Prepared by the Energy and Research Institutes for Ministry of NonConventional Energy sources, Government of India.

[21] WECS, 2010. Energy Sector synopsis Report. Kathmandu, Nepal: Water and Energy Commission Secretariat. 